\title{
A Review of Short-Term Cardiac Outcomes Associated with the Terrorist Attacks of September 11, 2001
}

\author{
Bernadette Royce ${ }^{1,2}$, Ira S. Richards ${ }^{1}$
}

${ }^{1}$ University of South Florida College of Public Health

${ }^{2}$ Commonwealth Health Emergency Medical Services

Firemed258@gmail.com

irichard@health.usf.edu

Abstract

Introduction: The terrorist attacks of September 11, 2001 resulted in significant adverse outcomes including cardiovascular disease. The increase in cardiovascular outcomes was both short-term and long-term. A review was conducted on the short-term increase in cardiovascular disease following the attacks.

Purpose: The main purpose of the study was to examine the short-term cardiovascular outcomes surrounding the events of September 11, 2001.

Methodology: A literature search of Medline and Google Scholar was conducted to locate peer-reviewed studies that focused on the short-term cardiovascular outcomes in the aftermath of September 11, 2001. The information was then collected and analyzed.

Results: The articles returned indicated that individuals both near the sites of the attacks and remote from the attacks suffered adverse cardiovascular outcomes in the aftermath of September 11, 2001.

Conclusion: While medical facilities close to a terrorist attack or other disaster expect to see adverse health outcomes following the event, medical facilities remote from the location may also see an increase in adverse health outcomes following an attack or disaster. Health facilities and emergency medical services in all locations need to be prepared for an increase in patients following a terrorist attack or other disaster.

Keywords: September 11, World Trade Center, terrorism, cardiovascular disease

\section{INTRODUCTION}

On September 11, 2001, the United States suffered a series of terrorist attacks, resulting in the death of 2,977 victims (Sayuk, \& Drossman, 2011). These attacks included the hijacking of planes that were then used to target specific structures, including the Twin Towers of the World Trade Center (WTC) in Manhattan, New York, the Pentagon in Washington D.C., and other unknown targets. In all, four planes were successfully hijacked. Two struck the Twin Towers, one struck the Pentagon, and the fourth plane crashed in a field in Pennsylvania. The attack on the Twin Towers resulted in their eventual collapse and the collapse of WTC Building 7. A massive plume of dust and particulate matter was released in the collapse. The dust included a wide range of toxins, including asbestos, polychlorinated biphenyls, polychlorinated dibenzodioxins, pesticides, phthalate esters, and other hydrocarbons (Lioy, et al, 2002).

Lower Manhattan, and the surrounding communities of New York City were covered with the dust and toxins, resulting in a significant health risk. One of the health risks associated with the collapse of the World Trade Center included in an increase in cardiovascular disease (CVD). CVD refers to a number of conditions that impact the heart and the blood vessels. It is the most common cause of death in the United States. CVD includes myocardial 
infarction, hypertension, coronary artery disease (CAD), congestive heart failure (CHF), atrial fibrillation, and stroke. It also includes the development of potentially life-threatening dysrhythmias such as ventricular tachycardia (VT) and ventricular fibrillation (VF) (Centers for Disease Control and Prevention, 2018)

The increase in CVD following the attacks was both immediate and long-term. A number of studies have been conducted on this increase. The immediate effects impacted individuals both at the site of "Ground Zero" as the World Trade Center site became known, and individuals in remote locations. This review focuses on the impact of September $11^{\text {th }}$ on the development of CVD. It seeks to examine the current knowledge regarding how these events impacted the cardiovascular health of individuals.

While important recent work on the health outcomes of September 11 has focused on the long-term effects of the events, it remains important to consider the short-term impact of the event, particularly with regards to CVD. As terrorism continues to increase around the world, including in the United States, the health care system must be prepared to respond to any increase in CVD even remote from the location of the terrorist attack. Mass shootings, such as the Orlando Pulse Massacre, the Las Vegas shootings, and the tragic continuance of school shootings, may increase the possibility of cardiac sequelae in locations both proximal and remote from the tragedies. Terrorism has been implicated as a cause of cardiac arrhythmias (Qureshi, et al, 2003). Anger and psychological stress may result in the development of polymorphic ventricular arrythmias in individuals who a have pre-disposed risk to these events (Lampert, 2010; Albert, et al, 2006). The health care system must also consider the likelihood of increased cardiac sequelae in the aftermath of natural disasters, such as earthquakes (Sado, et al, 2018; In order to be better prepared to respond to these health outcomes, a review was conducted on the immediate cardiac outcomes in the wake of the events of September 11, 2001.

\section{METHODS}

\section{Search Strategy}

A literature search utilized the PubMed and Google Scholar for studies on the development of cardiac sequelae in the immediate aftermath of the events of September 11, 2001. The search terms included: (World Trade Center) (September 11, 2001) AND (Cardiac Or Cardiovascular Or Hypertension). The references of returned articles were then examined for additional studies that were not located in the searches.

\section{Inclusion Criteria}

(1) full-length research articles; (2) published in English between October 1, 2001 and December 31, 2010; (3) acute health outcomes related to the cardiovascular system.

\section{Exclusion Criteria}

Articles that focused on the long-term health effects of September $11^{\text {th }}$ were excluded.

\section{RESULTS}

A number of studies indicated that the events of September 11, 2001 resulted in an increase in cardiovascular events, both in the immediate vicinity of World Trade Center and in areas remote from the attacks.

Near the World Trade Center, individuals suffered adverse cardiovascular outcomes in the aftermath of the terrorist attacks. According to Steinberg et al, (2004), the incidence of ventricular arrhythmias increased more than two-fold in patients with implantable cardiac defibrillator devices (ICDs). ICDs are implanted into individuals who are at risk for the development of potentially life-threatening cardiac dysrhythmias including ventricular fibrillation or ventricular tachycardia. ICDs store all serious cardiac events for several months afterwards. The study by Steinberg et al (2004) utilized this opportunity to examine whether or not ventricular dysrhythmias increased in the thirty-day period immediately following September 11, 2001. Two hundred 
patients with ICDs who presented for regularly scheduled visits after October 1, 2001 were recruited for the study. The data obtained for the thirty-day period following September 11, 2001 were compared with the data before the terrorist attacks. Preceding 9/11, 7 of the patients suffered an event. In the aftermath of 9/11, 16 had at least one event treated by the ICD. The risk of a cardiac event that is treatable by an ICD increased 2.3-fold in the immediate aftermath of $9 / 11$. In all incidents, the ICD successfully treated the life-threatening dysrhythmia. Interestingly, none of the events occurred in the first three days after 9/11.

An increase in defibrillator shocks was also noted remote from the site. Individuals with ICDs who were living in Florida at the time of the attacks were also examined to determine the incidence of TAs after 9/11. One-hundred thirty-two patients who presented for routine clinic examinations after October 11, 2001 were examined. The data were examined for the period thirty days before and thirty days after $9 / 11$. Any episodes of defibrillation or antitachycardia pacing (ATP) were verified. There was a 2.8 -fold increase in the risk of a TA in the month following fo $9 / 11$. After $9 / 11$, fourteen patients experienced a TA compared to only 5 patients in the 30 days before $9 / 11$ (Shedd, et al, 2004).

Several studies focused on cardiac hospitalizations in the aftermath of 9/11. Overall, the studies all indicated that hospitalizations for cardiovascular disease increased in the period immediately following the events of September 11.

Feng et al (2006) examined the cardiac sequelae in Brooklyn, New York, in the period following 9/11. They examined patients admitted to a hospital located four miles from the World Trade Center site for the period of sixty days both prior and after the terrorist attacks. A total of 1,653 admissions were examined by the researchers. Diagnostic categories included acute myocardial infarction (MI), unstable angina (UA), tachyarrhythmia (TA), and other cardiac concerns, including congestive heart failure and syncope in cardiac patients. The authors determined that cardiac diagnoses including MI and TA increased significantly in the period following 9/11. Unstable angina decreased in the aftermath. The authors concluded that stress may have caused a progression from UA to MI in cardiac patients.

Lin et al (2010) also examined cardiovascular hospitalizations, as well as respiratory hospitalizations post 9/11. The study compared residential areas in Manhattan and Queens, which served as a control area. Cardiovascular data indicated that the control area had a much higher baseline level of hospital admissions than the affected region. The authors determined that there were increases in cardiovascular admission rates beginning one week after $9 / 11$. However, the increase did not reach statistical significance.

The increases in cardiovascular disease were not isolated to Manhattan. Areas remote from Ground Zero also saw increases in cardiovascular events. One study examined the cardiac events in New Jersey emergency departments for sixty days before and after $9 / 11$ for a period of three years, including 2001 . The study focused MIs and TAs. A total of 571,079 patients were examined. In the sixty days immediately following $9 / 11$, there was a statistically significant increase in patients presenting with MIs. There was a $49 \%$ increase in MIs in the sixty days after $9 / 11$ when compared to the sixty days before $9 / 11$. The authors did not find any statistically significant increase in TAs for any year (Allegra, et al, 2005).

The impact of 9/11 on the incidence of MIs in Worcester, Massachusetts was also examined. The researchers determined that the daily average MIs was 3.4 in the period from January 1, 2001 to September 10, 2001. They noted a transient increase in the risk of MI on the day of the attacks and the following day. Overall, there was no statistically significant increase in MIs for the week of September 11, 2001 (Goldberg, et al, 2005).

In a documented isolated case, a state trooper in North Carolina learned about the terrorist attacks while he was wearing a halter monitor. There were immediate changes noted in his heart rate variability immediately after hearing about the attacks. His heart rate immediately increased while there was a corresponding decrease in the percentage of interval differences (Riediker, et al, 2005). 
Nationwide, there was an increase in physician-diagnosed cardiovascular ailments in the two- to three-years post $9 / 11$ when compared to a pre-9/11 online health survey. Individuals who reported a stress response to the events of $9 / 11 \mathrm{had}$ a $53 \%$ increased incidence of cardiovascular diseases in the three years post-9/11. This was the only national study that examined the impacts of terrorism and acute stress on the cardiovascular health of individuals (Holman, et al, 2008).

\section{DiscusSION}

In the aftermath of $9 / 11$, individuals both proximal and remote from sites of the terrorist attacks suffered a wide range of health concerns. Individuals who were proximal to the locations particularly Ground Zero, were exposed to a number of serious risks to health. However, those who were also remote from the locations also suffered from health risks, including an increase in cardiovascular disease. It is important to consider the potential etiologies of these conditions.

For individuals who were at Ground Zero, there were a number of potential cardiovascular risk factors. The significant stress of the event is only one of these risk factors. The exposure to particulate matter must also be considered. Exposure to particulate matter has been a documented risk factor in the development of cardiovascular disease (Brook, et al, 2010).

PM exposure is also known to adversely impact the heart rate variability (Pope, et al, 1999). A decrease in heart rate variability is associated with an increase in mortality after an MI (Kleiger, et al, 1987).

However, the terrorist attacks also led to increased feelings of anger in many individuals (Evans, et al, 2006). Anger is also associated with the development of TAs. The exact etiology of anger as a trigger for TAs is not completely understood at this time. The response of the body to strong emotions, such as anger, is a release of catecholamines and a decrease in vagal tone. The activation of the sympathetic system and the decrease in parasympathetic stimulation has been shown to by arrhythmogenic. T-wave alternans (TWA) has also been shown to increase as a result of mental stress and the increase of catecholamine release. The presence of TWA is considered important in the development of ventricular arrhythmias. Anger has been shown to cause in increase in TWA. Furthermore, the presence of anger-inducing TWA was predictive of future TAs that required conversion by an ICD (Lampert, 2010).

\section{CONCLUSION}

The events of September 11, 2001 continue to impact the health of many individuals who were directly exposed to the tragedy. However, studies have indicated that exposure resulting in cardiovascular disease occurred both proximally and remotely from the terrorist sites. Stressful events have been associated with an increase in cardiovascular episodes (Dimsdale, 2008). The literature available on cardiovascular events in the wake of 9/11 supports the hypothesis that stressful events can increase the risk of cardiovascular events, such as the development of TAs and MIs in individuals who are already at risk for cardiac events.

The world continues to experience terrorist events, mass shootings, war, and other situations that increase stress and anger for communities. Emergency medical services (EMS), emergency departments (EDs) and other health care providers rehearse dealing with disasters, such as active shooter events and terrorism. However, the evidence that adverse health outcomes occur in areas remote from the site of the disaster indicates that preparation by health care needs to be comprehensive and recognize the potential for increased cardiovascular disease in the aftermath of situations that may result in increased anger and stress in the public. They need to recognize that the event does not need to be a local event to result in an increase in cardiac patients. EMS, EDs, and interventional cardiac catherization facilities need to be prepared nationwide in the event of an event that increases stress for the community, regardless of the proximity of the event.

"The author(s) declare(s) that there is no conflict of interest regarding the publication of this paper.

American Research Journal of Public Health

Page 53 


\section{REFERENCES}

Albert, C. M., Lampert, R., Conti, J. B., Chung, M. K., Wang, P. J., Muller, J. E., \& Mittleman, M. A. Episodes of anger trigger ventricular arrhythmias in patients with implantable cardioverter defibrillators. Circulation. 2006; 114: 831.

Allegra, J. R., Mostashari, F., Rothman, J., Milano, P., \& Cochrane, D. G. Cardiac events in New Jersey after the September 11, 2001, terrorist attack. J Urban Health, 2005; 82(3): 358-363.

Brook, R. D., Rajagopalan, S., Pope, C. A., Brook, J. R., Bhatnagar, A., Diez-Roux, A. V., ... \& Peters, A. Particulate matter air pollution and cardiovascular disease: an update to the scientific statement from the American Heart Association. Circulation. 2010; 121(21): 2331-2378.

Centers for Disease Control and Prevention. “Heart Disease.” April 6, 2018. https://www.cdc.gov/heartdisease/ index.htm

Dimsdale, J. E. Psychological stress and cardiovascular disease. J. Am. Coll Cardiol. 2008; 51(13): 1237-1246.

Evans, S., Giosan, C., Patt, I., Spielman, L., \& Difede, J. Anger and its association to distress and social/occupational functioning in symptomatic disaster relief workers responding to the September 11, 2001, World Trade Center disaster. J Trauma. Stress. 2006: 19(1): 147-152.

Goldberg, R. J., Spencer, F., Lessard, D., Yarzebski, J., Lareau, C., \& Gore, J. M. Occurrence of acute myocardial infarction in Worcester, Massachusetts, before, during, and after the terrorists attacks in New York City and Washington, DC, on 11 September 2001. Am. J. Cardiol. 2005: 95(2): 258-260.

Holman, E. A., Silver, R. C., Poulin, M., Andersen, J., Gil-Rivas, V., \& McIntosh, D. N. Terrorism, acute stress, and cardiovascular health: A 3-year national study following the September 11th attacks. Arch Gen Psych. 2008: 65(1): 73-80.

Kleiger, R. E., Miller, J. P., Bigger, J. T., \& Moss, A. J. Decreased heart rate variability and its association with increased mortality after acute myocardial infarction. Am. J. Cardiol. 1987: 59(4): 256-262.

Lampert, R. Anger and ventricular arrhythmias. Curr. Opin Cardiol. 2010:, 25(1): 46.

Lin, S., Gomez, M. I., Gensburg, L., Liu, W., \& Hwang, S. A. Respiratory and cardiovascular hospitalizations after the World Trade Center disaster. Arch. Environ. Occup. Health. 2010: 65(1): 12-20.

Lioy, P. J., Weisel, C. P., Millette, J. R., Eisenreich, S., Vallero, D., Offenberg, J., ... \& Prophete, C. Characterization of the dust/smoke aerosol that settled east of the World Trade Center (WTC) in lower Manhattan after the collapse of the WTC 11 September 2001. Environ Health Perspect. 2001; 110(7): 703.

Qureshi, E. A., Merla, V., Steinberg, J., \& Rozanski, A. Terrorism and the heart: rimplications for arrhythmogenesis and coronary artery disease. Card. Electrophysiol Rev. 2003: 7(1): 80-84.

Pope, C. A., Verrier, R. L., Lovett, E. G., Larson, A. C., Raizenne, M. E., Kanner, R. E., ... \& Dockery, D. W. Heart rate variability associated with particulate air pollution. Am. Heart J. 1999: 138(5): 890-899.

Riediker, M., Herbst, M. C., Devlin, R. B., Griggs, T. R., Bromberg, P. A., \& Cascio, W. E. Effect of the September 11, 2001 terrorist attack on a state highway patrol trooper's heart rate variability. ANE. 2005: 10(1): 83-85.

Sado, J., Kiyohara, K., Iwami, T., Kitamura, Y., Ando, E., Ohira, T., ... \& Kitamura, T. (2018). Three-year follow-up after the Great East Japan Earthquake in the incidence of out-of- hospital cardiac arrest with cardiac origin. Circ. J. 2018: , 82(3): 919-922. 
A Review of Short-Term Cardiac Outcomes Associated with the Terrorist Attacks of September 11, 2001

Sayuk, G. S., \& Drossman, D. A. Gastroesophageal reflux symptoms in 9/11 survivors and workers: insights gained from tragic losses. Am. J. Gastroenterol: 2011: 106: 1942-1945.

Shedd, O. L., Sears Jr, S. F., Harvill, J. L., Arshad, A., Conti, J. B., Steinberg, J. S., \& Curtis, A. B. The World Trade Center attack: increased frequency of defibrillator shocks for ventricular arrhythmias in patients living remotely from New York City. J. Am Coll Cardiol. 2004: 44(6): 1265-1267.

Steinberg, J. S., Arshad, A., Kowalski, M., Kukar, A., Suma, V., Vloka, M., ... \& Reed, G. Increased incidence of lifethreatening ventricular arrhythmias in implantable defibrillator patients after the World Trade Center attack. J. Am Coll Cardiol. 2004: 44(6): 1261-1264.

Citation: Bernadette Royce, Ira S. Richards, "A Review of Short-Term Cardiac Outcomes Associated with the Terrorist Attacks of September 11, 2001". American Research Journal of Public Health; 1(1): 50-55.

Copyright (c) Bernadette Royce, Ira S. Richards, This is an open access article distributed under the Creative Commons Attribution License, which permits unrestricted use, distribution, and reproduction in any medium, provided the original work is properly cited. 